\title{
Adoptive immunotherapy for cytomegalovirus infection
}

\author{
Kei Numazaki, M D \\ Department of Pediatrics \\ Sapporo Medical University School of Medicine \\ S.1 W.16 Chuo-ku, Sapporo, 060-8543 Japan
}

\begin{abstract}
We reported a case with interstitial pneumonia associated with cytomegalovirus (CMV) infection in whom clinical improvement was observed after the treatment with primary adoptive immunotherapy. Although adoptive transfer of CMV-specific T cells offers the potential for reconstitution of viral immunity after allegoric transplantation, the logistics of producing virus-specific T-cell clones has limited the application of therapies.@JASEM
\end{abstract}

Under immunosuppressive conditions, latent or persistent cytomegalovirus (CMV) infection can be reactivated to produce a wide variety of clinical manifestations. Unfortunately, no successful antiviral treatment of pediatric CMV infection without displaying cytotoxicity has yet been developed. Adoptive transfer of antigen-specific cytotoxic $\mathrm{T}$ lymphocytes (CTLs) offers safe and effective therapy for certain viral infections.

Peggs and colleagues (2003) reported that they treated patients for CMV infection with polyclonal CMV-specific T-cell lines and that massive in-vivo expansions of CMV-specific cytotoxic T lymphocytes were observed, resulting in reconstitution of viral immunity.

\section{MATERIALS AND METHODS}

We reported a case with interstitial pneumonia associated with CMV infection in whom clinical improvement was observed after the treatment with primary adoptive immunotherapy (Numazaki et al., 1997). A 17-month-old girl was admitted because of cough and dyspnea. Her chest roentgenogram demonstrated interstitial pneumonic shadow. At this time serum IgG and IgM antibodies against CMV were detected and CMV was isolated from sputum and urine. CMV DNA was also detected from her peripheral blood mononuclear cells (PBMCs) by PCR.

Her PBMCs were separated from blood and cultured with immobilized anti-CD3 monoclonal antibody and human recombinant interleukin 2 (rIL-2).

\footnotetext{
*Corresponding author: E--mail: numazaki@sapmed.ac.jp

TEL: +81-11- 611-2111 EXT.3413

FAX: +81-11- 611-0352

Abstract available Online at http:// www.ajol.info
}

A rapid proliferation of $\mathrm{T}$ lymphocytes was obtained by this procedure. Cultured $\mathrm{T}$ lymphocytes were then transferred to a gas-permeable culture bag and culture continued for an additional 8 days with an increasing volume of medium. $\mathrm{T}$ cell numbers increased about 2000-hold during 2 weeks of culture. The final population contained about 30\% CD4+ and $60 \%$ CD8+ T lymphocytes. CD4+ $\mathrm{T}$ lymphocytes had cytotoxic activity as strong as CD8+ cells. T lymphocytes generated from her peripheral blood were administered intravenously to the patient in six doses $\left(4.3 \times 10^{8}\right.$ to $1.1 \times 10^{9}$ cells $)$ of a total of $4.03 \times 10^{10}$ cells.

\section{RESULTS AND DISCUSSIONS}

After the treatment with primary adoptive immunotherapy, chest radiograph showed resolution of infiltrates, CMV was not isolated from sputum and CMV DNA was not detected from PBMCs. Clinical symptoms and laboratory abnormal findings improved and CMV disappeared from clinical specimens after the treatment with primary adoptive immunotherapy. The virus-specific CD8+ cytotoxic and CD4+ helper or cytotoxic $\mathrm{T}$ cells may be amplified and used to control CMV infection.

Walter and colleagues (1995) provides important evidence that infusion of donor-derived CD8+ cytotoxic T-cell clones specific for CMV can promptly reconstitute cellular immunity against CMV in recipients of allogenic bone marrow, thus reducing the risk of morbidity and mortality related to viral infection. However, the persistence of transferred CD8+ cytotoxic cells was prompted by the recovery of the response of CD4+ CMV-specific helper $\mathrm{T}$ cells. 
The infusion of virus-specific polyclonal T-cell lines containing both CD4+ and CD8+ cells has been successfully used to control infection with Epstein-Barr virus (EBV) and related lymphoproliferative disorders of recipients of allogenic bone marrow (Rooney et al., 1995). Locatelli and colleagues (1996) suggested that donor-derived polyclonal T-cell lines enriched with CMV-reactive $\mathrm{T}$ cells might be also useful for the reconstitution of immunity.

As Peggs and colleagues (2003) report, although adoptive transfer of CMV-specific T cells offers the potential for reconstitution of viral immunity after allegoric transplantation, the logistics of producing virus-specific T-cell clones has limited the application of therapies.

\section{REFERENCES}

Locatelli F, Maccario R, Gerna G (1996). Anticytomegalovirus T-cell clones. $N$ Engl $J$ Med 334: 601.
Numazaki K, Ikehata M, Yanai S (1997). Adoptive immunotherapy for interstitial pneumonia associated with cytomegalovirus infection. Clin Infect Dis 25: 1246-47.

Peggs KS; Verfuerth S; Pizzey A (2003). Adoptive cellular therapy for early cytomegalovirus infection after allogeneic stem-cell transplantation with virus-specific T-cell lines. Lancet 362: 1375-1377 .

Rooney CM, Smith CA, Ng CY (1995). Use of gene-modified virus-specific $\mathrm{T}$ lymphocytes to control Epstein-Barr-virus-related lympho-proliferation. Lancet 345: 9-13.

Walter EA, Greenberg PD, Gilbert MJ(1995). Reconstitution of cellular immunity against cytomegalovirus in recipients of allogenic bone marrow by transfer of $\mathrm{T}$-cell clones from the donor. $N$ Engl J Med 333: 1038-1044. 